\title{
Security Amalgamation using Cloud Computing
}

\author{
D.Jeyapriya S.Theivasigamani, R.Velvizhi, P.Nandhini
}

\begin{abstract}
The Huge measure of substance data available should be composed along these lines keeping up a vital separation from the misuse of storage space, which can be expert by equivalent join framework. In this paper, we propose, near join strategy, which is an in light of Map Reduce structure used is uses strings for tantamount join and support set based and character based functionalities. Key regard sets are made using marks. Association based count can be used execute, which unite broad number of noteworthy worth key sets which aide decreases the transmission cost. Here we are using "light-weight" channel units to grow the execution, which generally trims huge number of various regard key sets with less transmission cost.
\end{abstract}

Index Terms: Data Integration; Map Reduce; similar Join; Hadoop

\section{INTRODUCTION}

The mark age in comparative join calculation should be possible utilizing two strategies. Position known strategy and multi coordinate cognizant technique. Both the can be utilized together as half breed technique to create the marks. These strategies will diminish the quantity of mark age altogether and keeps away from false negatives. [1],[3],[5]

Revised Manuscript Received on June 22, 2019.

D.Jayapriya , Department of CSE ,Bharath Institute of Higher Education and Reaesrch,Chennai,Thamilnadu,India.

S.Deivasigamani ,Deparrtment of CSE, Bharath Institute of Higher Education and Research Chenai,Thamilnadu ,India.

R.Velvizhi , Department of CSE ,Bharath Institute of Higher Education and Reaesrch,Chennai,Thamilnadu,India.

P.Nandhini ,Deparrtment of CSE, Bharath Institute of Higher Education and Research Chenai,Thamilnadu ,India.

\section{CHANNEL ORGANIZE}

Channel organize comprises of Map stage first and Reduce stage second. The competitor sets are produced utilizing the strategies clarified in signature age organize. In Map stage, marks are considered as keys and strings as qualities. Since two same comparable strings have same key, they are fought to same decrease errand. Too, strings are supplanted by string ids which decrease transmission cost. In diminish stage, esteem key sets are considered as info which comprises of mark and strings list containing the mark. At that point it isolates the rundown into two gatherings for <aid> and <bid>.[2 ],[4],[6]

\section{CHECK ARRANGE}

The Verification organize comprises of two phases as found in Fig. 2. Both the stages again performs Map and Reduce works in which it dispenses with the copies hopeful sets which were produced because of two strings sharing different mark. The string ids will be supplanted by unique strings to check the competitor sets. [7],[9],[11]

\section{CONSOLIDATION BASED ALGORITHMS}

The Similar join calculation produces extensive number marks in view of significant worth key sets. The primary objective of the consolidation based calculation to lessen the quantity of significant worth key sets. This strategy decreases the trimming power on the grounds that the sub string and the fragment might coordinate at various begin positions or with various lengths. In both the cases, the false positives will get produced. Thus a similar pruning force ought to be held as comparable join calculation by checking the begin position of the substring and length of the string are inside the limits. Keeping in mind the end goal to productively blend the first esteem key sets to get the new esteem key sets, read the string once to create all esteem enter sets and in decrease stage split the info esteem list into tow records to create the yield. [8],[ $10],[12]$

\section{LIGHT-WEIGHT FILTERS UNITS}

The transmission cost and handling cost in the check arrange is high to create the applicant sets. Thus light-weight channel units are utilized for the most part to decrease the quantity of competitor sets. In Map stage phase of channel, append the first string for values field in every <value, key> sets. Similar Join calculation for strings comparative join depends on Guide Reduce which is executed by consolidating blend calculation and utilized the light weight channels for character based comparable capacities and set comparable capacities. By utilizing consolidate calculation, the quantity of significant worth key sets are diminished to substantial number degree, without decreasing the trimming power. Light weight channel units decreases the quantity of competitor sets, which will

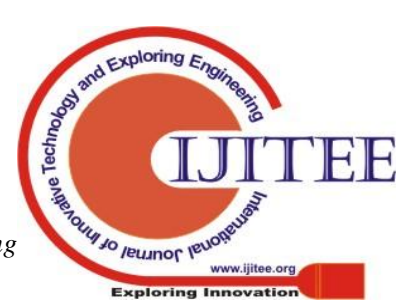


builds the execution and diminishes the transmission cost. The Similar join calculation is capable now to process both short strings and huge recordsmilar Join calculation for strings comparative join depends on [13], [15] ,[ 17] [14],[ 16], [18].

Guide Reduce which is executed by consolidating blend calculation and utilized the light weight channels for character based comparable capacities and set comparable capacities. By utilizing consolidate calculation, the quantity of significant worth key sets are diminished to substantial number degree, without decreasing the trimmingpower. Light weight channel units decreases the quantity of competitor sets, which will builds the execution and diminishes the transmission cost. The Similar join calculation is capable now to process both short strings and huge records[19],[21],[23],[37],[39],[41]

\section{MATERIAL AND METHODOLOGY}

Current day PC applications have a need to get to, process, report and uncommonly incorporate information from [38],[40]different and dissimilar sources. The information sources are made, kept up and distributed in positions that hold fast to their own particular association particular norms. Information reconciliation frameworks mean to give a solitary bound together interface to consolidating information in different configurations from those various sources. One of the primary methodologies in the combination of information is to utilize a Data Warehouse, where information from numerous information sources are extricated, changed and anticipated as another database, which is an accumulation of perspectives containing information. The information in the Data Warehouse might be organized uniquely in contrast to the source. Information is not new as the heap occurs at booked circumstances. Another type of information joining includes peers trading information in light of specific mappings. At the point when a question is postured to a companion, it sends its information and additionally imports information from different associates. The information trade is an iterative procedure wherein each companion can thus import information from its neighboring associates in view of put stock seeing someone and there is no focal part dealing with the exchange of information. The information incorporation approach we talk about in this exploration work is the intervention framework or virtual information coordination framework that offers an inquiry interface over a solitary worldwide mapping. The worldwide diagram comprises of social predicates, as far as which the client can posture questions. In any case there is no genuine information contained in them. [20],[22], [24]

\section{RESULTS AND DISCUSSIONS}

At the point when the go between gets an inquiry as far as the worldwide relations, it creates a question arrange for that distinguishes the applicable information sources and the significant information in them, and indicates how the information got from them must be joined to assemble the last answer. To deliver such an arrangement, the arbiter stores and procedures certain mappings or view definitions that partner the predicates in the worldwide diagram with those in the neighborhood sources. The Local-As-View (LAV) approach, which is utilized as a part of this examination work, characterizes the neighborhood source relations as perspectives over the worldwide construction .along these lines, each pertinent source connection can be characterized autonomously from other source relations. Thusly, it is less demanding for any source to join or leave the framework, without influencing other source definitions. The structure of the worldwide pattern and mappings constitute the metadata in a go between framework. The metadata will likewise [32],[34],[36]contain imperatives and points of interest for getting to the information sources. The metadata depicts the idea of the information sources and information contained in them. The effective usage of a question arranging component depends on a legitimate outline, portrayal and questioning of metadata to separate required data. There are three primary calculations that plan to give question revamping under the LAV [31],[33],[35] approach. The Bucket Algorithm actualized in the Information Manifold go between considers inquiries and view definitions that are conjunctive questions with examination predicates. On account of the Extended Minicon Algorithm, the inquiries and view definitions are conjunctive questions with correlation predicates. The great Inverse-RulesAlgorithm (IRA) acknowledges see definitions without correlation predicates yet handles utilitarian conditions, recursive inquiries and restricting example constraints. [25],[27],[29]

\section{VIII.CONCLUSIONS}

In stock relations, information from various sources is acquired in various archive designs and is put away in the information distribution center. These qualities are gotten by the client at various purpose of time. Likewise, the individual question postured by the client acquires values from the solid shape. The $3 \mathrm{D}$ shape is produced by bury relating the different document designs. The qualities for the question is acquired from the database are it is as of now present or amassed esteem is given. Various leveled display is utilized to bore down the database and get exact outcome. At least two records are entomb related and in view of the esteem show the outcome is given to the client. [26],[28],[30]

\section{REFERENCES}

[1] Kumarave A., Rangarajan K.,Algorithm for automaton specification for exploring dynamic labyrinths,Indian Journal of Science and Technology,V-6,I-SUPPL5,PP-4554-4559,Y-2013

[2] P. Kavitha, S. Prabakaran "A Novel Hybrid Segmentation Method with Particle Swarm Optimization and Fuzzy C-Mean Based On Partitioning the Image for Detecting Lung Cancer" International Journal of Engineering and Advanced Technology (IJEAT) ISSN: 2249-8958, Volume-8 Issue-5, June 2019

[3] Kumaravel A., Meetei O.N.,An application of non-uniform cellular automata for efficient cryptography,2013 IEEE Conference on Information and Communication Technologies, ICT 2013,V-,I-,PP-1200-1205,Y-2013

[4] Kumarave A., Rangarajan K.,Routing alogrithm over semi-regular tessellations,2013 IEEE Conference on Information and Communication Technologies, ICT 2013,V-,I-,PP-1180-1184,Y-2013

[5] P. Kavitha, S. Prabakaran "Designing a Feature Vector for Statistical Texture Analysis of Brain Tumor" International Journal of Engineering and Advanced

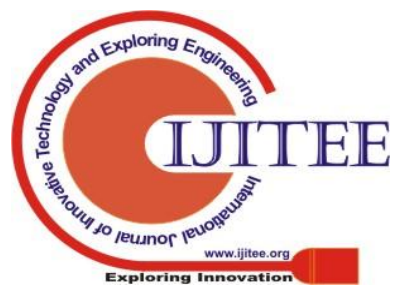
$\&$ Sciences Publication 
Technology (IJEAT) ISSN: 2249-8958, Volume-8 Issue-5, June 2019

[6] Dutta P., Kumaravel A.,A novel approach to trust based identification of leaders in social networks,Indian Journal of Science and Technology,V-9,I-10,PP--,Y-2016

[7] Kumaravel A., Dutta P.,Application of Pca for context selection for collaborative filtering,Middle - East Journal of Scientific Research,V-20,I-1,PP-88-93,Y-2014

[8] Kumaravel A., Rangarajan K.,Constructing an automaton for exploring dynamic labyrinths,2012 International Conference on Radar, Communication and Computing, ICRCC 2012,V-,I-,PP-161-165,Y-2012

[9] P. Kavitha, S. Prabakaran "Adaptive Bilateral Filter for Multi-Resolution in Brain Tumor Recognition" International Journal of Innovative Technology and Exploring Engineering (IJITEE) ISSN: 2278-3075, Volume-8 Issue-8 June, 2019

[10] Kumaravel A.,Comparison of two multi-classification approaches for detecting network attacks, World Applied Sciences Journal,V-27,I-11,PP-1461-1465,Y-2013

[11] Tariq J., Kumaravel A.,Construction of cellular automata over hexagonal and triangular tessellations for path planning of multi-robots,2016 IEEE International Conference on Computational Intelligence and Computing Research, ICCIC 2016,V-,I-,PP--,Y-2017

[12] Sudha M., Kumaravel A.,Analysis and measurement of wave guides using poisson method,Indonesian Journal of Electrical Engineering and Computer Science,V-8,I-2,PP-546-548,Y-2017

[13] Ayyappan G., Nalini C., Kumaravel A.,Various approaches of knowledge transfer in academic social network,International Journal of Engineering and Technology,V-,I-,PP-2791-2794,Y-2017

[14] Kaliyamurthie, K.P., Sivaraman, K., Ramesh, S. Imposing patient data privacy in wireless medical sensor networks through homomorphic cryptosystems 2016, Journal of Chemical and Pharmaceutical Sciences 92.

[15] Kaliyamurthie, K.P., Balasubramanian, P.C. An approach to multi secure to historical malformed documents using integer ripple transfiguration 2016 Journal of Chemical and Pharmaceutical Sciences9 2

[16] A.Sangeetha,C.Nalini,"Semantic Ranking based on keywords extractions in the web", International Journal of Engineering \& Technology, 7 (2.6) (2018) 290-292

[17] S.V.GayathiriDevi,C.Nalini,N.Kumar,"An efficient software verification using multi-layered software verification tool "International Journal of Engineering \& Technology, 7(2.21)2018 454-457

[18] [18] C.Nalini,ShwtambariKharabe,"A Comparative Study On Different Techniques Used For Finger - Vein Authentication", International Journal Of Pure And Applied Mathematics, Volume 116 No. 8 2017, 327-333, Issn: 1314-3395

[19] M.S. Vivekanandan and Dr. C. Rajabhushanam, "Enabling Privacy Protection and Content Assurance in Geo-Social Networks", International Journal of Innovative Research in Management, Engineering and Technology, Vol 3, Issue 4, pp. 49-55, April 2018.

[20] Dr. C. Rajabhushanam, V. Karthik, and G. Vivek, "Elasticity in Cloud Computing", International Journal of Innovative Research in Management, Engineering and Technology, Vol 3, Issue 4, pp. 104-111, April 2018.

[21] K. Rangaswamy and Dr. C. Rajabhushanamc, "CCN-Based Congestion Control Mechanism In Dynamic Networks", International Journal of Innovative Research in Management, Engineering and Technology, Vol 3, Issue 4, pp. 117-119, April 2018.

[22] Kavitha, R., Nedunchelian, R., "Domain-specific Search engine optimization using healthcare ontology and a neural network backpropagation approach", 2017, Research Journal of Biotechnology, Special Issue 2:157-166

[23] Kavitha, G., Kavitha, R., "An analysis to improve throughput of high-power hubs in mobile ad hoc network" ,2016, Journal of Chemical and Pharmaceutical Sciences, Vol-9, Issue-2: 361-363

[24] Kavitha, G., Kavitha, R., "Dipping interference to supplement throughput in MANET", 2016, Journal of Chemical and Pharmaceutical Sciences, Vol-9, Issue-2: 357-360

[25] Michael, G., Chandrasekar, A.,'Leader election based malicious detection and response system in MANET using mechanism design approach", Journal of Chemical and Pharmaceutical Sciences(JCPS) Volume 9 Issue 2, April - June 2016.

[26] Michael, G., Chandrasekar, A.,"Modeling of detection of camouflaging worm using epidemic dynamic model and power spectral density", Journal of Chemical and Pharmaceutical Sciences(JCPS) Volume 9 Issue 2, April - June 2016

[27] Pothumani, S., Sriram, M., Sridhar, J., Arul Selvan, G., Secure mobile agents communication on intranet,Journal of Chemical and Pharmaceutical Sciences, volume 9, Issue 3, Pg No S32-S35, 2016
[28] Pothumani, S., Sriram, M., Sridhar, Various schemes for database encryption-a survey, Journal of Chemical and Pharmaceutical Sciences, volume 9, Issue 3, Pg NoS103-S106, 2016

[29] Pothumani, S., Sriram, M., Sridhar, A novel economic framework for cloud and grid computing, Journal of Chemical and Pharmaceutical Sciences, volume 9, Issue 3, Pg No S29-S31, 2016

[30] Priya, N., Sridhar, J., Sriram, M. "Ecommerce Transaction Security Challenges and Prevention Methods- New Approach” 2016 ,Journal of Chemical and Pharmaceutical Sciences, JCPS Volume 9 Issue 3.page no:S66-S68

[31] ]Priya, N.,Sridhar,J.,Sriram, M."Vehicular cloud computing security issues and solutions" Journal of Chemical and Pharmaceutical Sciences(JCPS) Volume 9 Issue 2, April - June 2016

[32] Priya, N., Sridhar, J., Sriram, M. "Mobile large data storage security in cloud computing environment-a new approach" JCPS Volume 9 Issue 2. April - June 2016

[33] Anuradha.C, Khanna.V, "Improving network performance and security in WSN using decentralized hypothesis testing "Journal of Chemical and Pharmaceutical Sciences(JCPS) Volume 9 Issue 2, April - June 2016.

[34] Anuradha.C, Khanna.V, "A novel gsm based control for e-devices" Journal of Chemical and Pharmaceutical Sciences(JCPS) Volume 9 Issue 2, April - June 2016

[35] Anuradha.C, Khanna.V, "Secured privacy preserving sharing and data integration in mobile web environments " Journal of Chemical and Pharmaceutical Sciences(JCPS) Volume 9 Issue 2, April - June 2016.

[36] Sundarraj, B., Kaliyamurthie, K.P. Social network analysis for decisive the ultimate classification from the ensemble to boost accuracy rates2016 International Journal of Pharmacy and Technology 8

[37] Sundarraj, B., Kaliyamurthie, K.P. A content-based spam filtering approach victimisation artificial neural networks 2016 International Journal of Pharmacy and Technology 83.

[38] Sundarraj, B., Kaliyamurthie, K.P. Remote sensing imaging for satellite image segmentation 2016 International Journal of Pharmacy and Technology $8 \quad 3$.

[39] Sivaraman, K., Senthil, M. Intuitive driver proxy control using artificial intelligence 2016 International Journal of Pharmacy and Technology 84 .

[40] Sivaraman, K., Kaliyamurthie, K.P. Cloud computing in mobile technology 2016 Journal of Chemical and Pharmaceutical Sciences 92.

[41] Sivaraman, K., Khanna, V. Implementation of an extension for browser to detect vulnerable elements on web pages and avoid click jacking 2016 Journal of Chemical and Pharmaceutical Sciences 92.

\section{AUTHORS PROFILE}

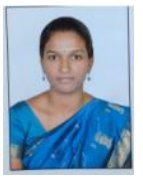

D.Jayapriya, Department of CSE ,Bharath Institute of Higher Education and Reaesrch,Chennai,Thamilnadu,India.

S.Theivasigamani ,Deparrtment of CSE, Bharath Institute of Higher Education and Research Chenai,Thamilnadu ,India

R.Velvizhi ,Deparrtment of CSE, Bharath Institute of Higher Education and Research Chenai,Thamilnadu ,India

P.Nandhini ,Deparrtment of CSE Bharath Institute of Higher Education and Research Chenai,Thamilnadu ,India 